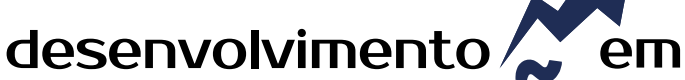 QUESTAOO
}

\section{COMUNIDADES QUE SUSTENTAM A AGRICULTURA (CSAs): Materializando o Associativismo Sustentável e a Economia Solidária?!}

\author{
http://dx.doi.org/10.21527/2237-6453.2021.57.11935
}

Recebido em: 13/1/2021

Aceito em: 29/6/2021

\section{Denilson Bertolaia ${ }^{1}$ Oriowaldo Queda², Maria Lúcia Ribeiro³}

\begin{abstract}
RESUMO
A aliança entre consumidores buscando alimentos saborosos, nutritivos e orgânicos e os agricultores familiares, desvalorizados social, econômica e culturalmente, representa um passo significativo no momento atual, pois pactua com um organismo agrícola sustentável, denominado, no Brasil, Comunidades que Sustentam a Agricultura (CSAs). Esse modelo agrícola orgânico e natural, de circuito curto de produção, que elimina atravessadores, é alicerçado nos valores da economia solidária, da autogestão e da ajuda mútua. O presente artigo tem como objetivo avaliar a sustentabilidade das CSAs pesquisadas nas dimensões social, ambiental e econômica, buscando constatar a efetividade dos princípios e dos valores da economia solidária. Como lócus da pesquisa foram determinadas duas comunidades do Estado de São Paulo. O desenho metodológico compreendeu visitas às CSAs e a aplicação de questionários destinados aos agricultores responsáveis pelas CSAs abordando as seguintes categorias: constituição, produção, registros e contabilidade. Foram trabalhadas pesquisas qualitativa e quantitativa como metodologias para descrever as ações dos gestores, o período e as regiões estudadas, bem como para aferir as similaridades e as diferenças numéricas das CSAs. Assim, constatou-se que essas organizações são constituídas; funcionam há mais de cinco anos; têm área superior a quatro hectares e meio; são constituídas por mais de três agricultores e de 35 coagricultores; os agricultores são assalariados; e não usam agrotóxicos. Esses resultados permitiram estabelecer parâmetros para subsidiar melhorias e aperfeiçoamentos na funcionalidade das CSAs pesquisadas por meio da apresentação de propostas para otimizar recursos e de avanços nas pesquisas acadêmicas em prol desses modelos de organismos agrícolas.
\end{abstract}

Palavras-chave: Desenvolvimento regional; socioambiental; agricultura familiar; gestão compartilhada; ajuda mútua.

COMMUNITIES THAT SUPPORT AGRICULTURE (CSAs): MATERIALIZING SUSTAINABLE ASSOCIATION AND THE SOLIDARY ECONOMY?!

\begin{abstract}
The alliance between consumers looking for tasty, nutritious and organic foods and family farmers, socially, economically and culturally undervalued, represents a significant step at the moment, as they agree with a sustainable agricultural body, called, in Brazil, Communities that Support Agriculture (CSAs). This organic and natural agricultural model, with a short production circuit, which eliminates middlemen, is based on values of solidarity economy, self-management and mutual help. This article aims to assess the sustainability of CSAs surveyed in the social, environmental and economic dimensions, seeking to verify the effectiveness of the principles and values of the solidarity economy. As the locus of the research, two communities in the State of São Paulo were determined. The methodological design included visits to CSAs and the application of questionnaires for farmers responsible for CSAs, covering the following categories: constitution, production, records and accounting. Qualitative and quantitative research were used as methodologies to describe the actions of the managers, the period and the regions studied, as well as to assess the similarities and numerical differences of the CSAs. Thus, it was found that these organizations are constituted; have been operating for more than five years; have an area of more than four and a half hectares; they are made up of more than three farmers and 35 co-farmers; farmers are wage earners; and do not use pesticides. These results allowed the establishment of parameters to support improvements, including in the functionality of the CSAs surveyed through the presentation of proposals to optimize resources and advances in academic research in favor of these models of agricultural organisms.
\end{abstract}

Keywords: Regional development; socio-environmental; family farming; shared management; mutual help.

\footnotetext{
${ }^{1}$ Doutorando no PPG em Desenvolvimento Territorial e Meio Ambiente da Universidade de Araraquara - UNIARA. Serventuário da Justiça do Tribunal de Justiça do Estado de São Paulo. dbertolaia@hotmail.com.

2 PPG em Desenvolvimento Territorial e Meio Ambiente da Universidade de Araraquara - Uniara. quedaoriowaldo@gmail.com

${ }^{3}$ Autora correspondente. Centro Universitário de Araraquara - Mestrado em Desenvolvimento Regional e Meio Ambiente. Rua Voluntários da Pátria, 1309 - Centro. CEP 14801-320. Araraquara/SP, Brasil. http://lattes.cnpq.br/4093825086696897. https:// orcid.org/0000-0002-3654-8831.ml.ribeiro@unesp.br
} 


\section{INTRODUÇÃO}

O homem depende do meio ambiente para seu desenvolvimento intelectual, moral, social e espiritual. Assim anuncia o primeiro item da Declaração da Conferência da Organização das Nações Unidas sobre o Meio Ambiente Humano de Estocolmo em 1972.

Nesse contexto de meio ambiente e crescimento humano, surge o desenvolvimento sustentável que, também, é um Direito Fundamental editado no primeiro princípio da Declaração do Rio sobre Meio Ambiente e Desenvolvimento em 1992, conhecida por "RIO + 20", ratificada pelo governo brasileiro.

Dessa forma, consequentemente cresce o número de consumidores conscientes que buscam a "saúde integral por meio do bem-estar físico, psicológico e social" - conceito de Saúde estabelecido pela Organização Mundial de Saúde (OMS). No Brasil, o meio ambiente harmonioso é um Direito Fundamental Constitucional, conforme artigo 225 da Carta Magna, devendo o Estado criar políticas públicas e ferramentas para esse fim.

A nova geração de agricultura 4.0 está ganhando espaço no agronegócio, pois agrega as tecnologias da informática e da internet, e as captações de dados são realizadas em tempo real até por drones. Dessa forma, busca o aumento da produtividade com qualidade, satisfazendo o consumidor, cada vez mais exigente e orgânico.

Nessa linha, classifica-se que a agricultura 1.0 é a tradicional, com mão de obra humana e animal; já na 2.0 há o uso de máquinas manuais e agrotóxicos; enquanto a 3.0 é a de precisão, com a mecanização (SORDI; VAZ, 2021).

Esses almejados alimentos saudáveis são cultivados, também, por agricultores familiares ou empreendedores familiares rurais, que devem ter até quatro módulos fiscais, usar mão de obra predominante familiar, ter rendas desse imóvel e dirigir, pessoalmente, as suas atividades agrícolas para que possam usufruir da Política Nacional da Agricultura Familiar (artigo $3^{\circ}$ da Lei Federal n. 11.326, de 24 de julho de 2006).

Nessa linha, originam-se as Comunidades que Sustentam a Agricultura (CSAs), nas quais os consumidores, ora coprodutores, compram a safra anual ou semestral do agricultor orgânico ou natural, pagando, mensalmente, determinado valor em dinheiro atribuído como "cota". Em contrapartida, recebem, semanalmente, determinada quantidade de frutas, legumes e verduras da época, ora denominadas "cestas".

As CSAs são compostas por organismos agrícolas que desenvolvem diversidade, integração e autossustentabilidade por meio de seus diversos departamentos, de parceiros e do uso de recursos naturais produzidos na própria área rural. Trata-se de um contexto relacional entre coprodutores e agricultores que aplicam os princípios de ajuda mútua, diversificação das culturas, aceitação dos alimentos da época, concessão mútua na decisão dos preços justos, relações de amizade, distribuição independente, organização e gestão compartilhada, aprendizagem mútua, cultivo e consumo local (HENDERSON; VAN EN, 2007).

Esse modelo agrícola sustentável, eliminador de atravessadores, por se tratar de um circuito curto de produção, promove a geração de renda e alimenta a dignidade do agricultor por meio do cultivo de frutas, legumes e hortaliças orgânicas sem o uso de agrotóxicos e de fertilizantes químicos. Nessa linha produtiva, o referido organismo agrícola é caracterizado por alguns parâmetros: diversidade, lidando com animais, vegetais e policultura; integração, pelo cultivo 
dos alimentos para os animais e pelo uso do esterco como adubo orgânico; e autosustentabilidade, por produzir tudo que é necessário por meio da terra e da água (HENDERSON; VAN EN, 2007).

É necessário ressaltar que os CSAs são, também, determinados pelos pilares ou dimensões da sustentabilidade. O pilar "ser socialmente justo" advém da prática do preço justo, em que agricultor e coagricultor decidem sobre o preço mensal das cestas, incluindo eventuais prejuízos e perdas, somados ao lucro merecedor. Advém, ainda, da autogestão no compartilhamento das deliberações colegiadas.

Já a dimensão "ambientalmente equilibrada" é promovida pelo não uso de agrotóxicos e de fertilizantes químicos, pois as CSAs utilizam o Sistema Agroflorestal (SAF), em que o cultivo é feito na mata, respeitando os ecossistemas. Por fim, estabelece-se o aspecto "economicamente viável", uma vez que o preço da cota é justamente acordado.

Historicamente, o movimento das CSA teve início no Japão, denominado Teikei, e foi disseminado pela França como Association pour le Maintien de l'Agriculture Paysanne (Amap), por Portugal como Relação de Cidadania entre Produtores e Consumidores (Reciproco), pela Itália como Gruppi di Acquisto Solidale (GAS); pelo Canadá como Agriculture Soutenue par la Communauté (ASC) e pelos EUA como Community Supported Agriculture (CSA).

No Brasil, esse conceito estabeleceu-se na década de 90 do século 20 em Fortaleza-CE, onde foi criada, inicialmente, a Associação para o Desenvolvimento da Agricultura Orgânica (Adao), a qual, entretanto, não criou raízes nem prosperou. Assim, ficou em dormência, até que, em 2011, por meio do alemão Hermann Pohlmann ${ }^{4}$, fundou-se a CSA Demétrio, no município de Botucatu-SP, servindo de modelo de CSA no Brasil (HENDERSON; VAN EN, 2007).

Dessa forma, essa estrutura agrícola orgânica, que protege o ambiente, ainda encontra amparo no Princípio do Estado Socioambiental de Direito, que eleva, constitucionalmente, a proteção do meio ambiente, sem qualquer tipo de hierarquia, à espécie de coluna de ostentação do Estado de Direito e da Democracia. Esse princípio, consequentemente, pode se ramificar em outros, como da dignidade da pessoa humana (mínimo existencial socioambiental ou ecológico), da solidariedade, da subsidiariedade e do desenvolvimento social.

O presente artigo apresenta como objetivo a avaliação da sustentabilidade sob as dimensões ecológica, econômica e social das CSAs Iperó, São José dos Campos, Demétria e Bauru, localizadas no Estado de São Paulo, buscando constatar a efetividade dos princípios e dos valores da economia solidária bem como aferir a tipicidade de organizações solidárias sob a tese de Paul Singer.

A CSA é um novo modelo de produção agrícola no Brasil. Por isso, ainda, não se estabeleceu um consenso sobre sua definição e conceito. Trata-se de uma área de bibliografia escassa, observando-se que esse modelo produtivo sofre adaptações ligadas à cultura e aos costumes de cada país ou região.

\footnotetext{
${ }^{4}$ Possui graduação em Design com ênfase em Sustentabilidade - Fachhochschule Muenster - Alemanha (1988) e Mestrado em Master of Fine Arts. M.F.A. - Alanus Hochschule - Alemanha (2011) com o tema Agricultura Sustentada pela Comunidade (CSA - Community Supported Agriculture) feito como uma obra de arte.
} 
Dessa forma, as CSAs têm como objetivos ${ }^{5}$ :

Generar prototipos de economía alternativa y sistemas alimentarios localizados, como modelos de organización económica para la sostenibilidad social y ecológica. Y especialmente permitir un trabajo digno y reconocido para las personas productoras, y una alimentación justa, saludable, accesible y de calidad para toda la sociedad; lo que denominamos "justicia alimentaria" (HENDERSON; VAN EN, 2007, p. 10).

Nesse contexto, prioriza-se a economia alternativa e a produção agrícola local, sustentável e que respeite a justiça alimentar. Já na Europa, a CSA é denominada Agriculture Supported Community (ASC), e seus modelos de projetos podem ser definidos como ${ }^{6}$ :

Acuerdos de largo plazo - al menos un año - entre producción y consumo; con cestas de temporada como el sistema básico de distribución de los alimentos; manejo agroecológico, certificado o no; existencia de sistemas o herramientas para compartir riesgos entre producción y consumo, tales como el pago de cuotas fijas independientes de la producción, o prepago de las cuotas al inicio de la temporada; y compromiso del consumo en la distribución, la administración y la toma de decisiones acerca de la producción e la economía del proyecto, junto con las personas productoras (HENDERSON; VAN EN, 2007, p. 10).

Nessa linha, realça-se que há um acordo de produção e de consumo agroecológico compartilhando a administração e as deliberações, mas é indiferente à certificação. Em 2016, no entanto, foi criada a rede "Urgenci-Europa" em prol do movimento Europeu da ASC, que formata a respectiva definição comum?:

La Agricultura Sostenida por la Comunidad (ASC) es una asociación directa, basada en la relación humana, entre personas consumidoras y una o varias personas productoras, en la que los riesgos, responsabilidades y beneficios generados em la actividad agraria son compartidos, a través de un acuerdo de compromiso en el largo plazo (HENDERSON; VAN EN, 2007, p. 10).

Esse é um conceito mais completo, o qual realça que a CSA tem a natureza jurídica de uma associação direta e humana, em que todos compartilham as obrigações e os riscos da produção num acordo de compromisso.

Nesse mesmo sentido, reforçando a ideia de compartilhar os riscos e as recompensas da produção, a imprensa escrita encaminha o trabalho sobre O que é CSA? Assim, a revista "Soil

\footnotetext{
${ }_{5}^{5}$ Tradução: "gerar protótipos de economia alternativa e sistemas alimentares localizados, como modelos de organização econômica para a sustentabilidade social e ecológica. E, principalmente, para permitir um trabalho decente e reconhecido aos produtores e uma dieta justa, saudável, acessível e de qualidade para toda a sociedade; o que chamamos de "justiça alimentar'".

${ }^{6}$ Tradução: "acordos de longo prazo - pelo menos um ano - entre produção e consumo; com cestas sazonais como sistema básico de distribuição de alimentos; manejo agroecológico, certificado ou não; existência de sistemas ou ferramentas para compartilhar riscos entre produção e consumo, como pagamento de cotas fixas independentes da produção ou pagamento antecipado de cotas no início da temporada; e comprometimento com o consumo na distribuição, administração e tomada de decisões sobre a projeção e economia do projeto, juntamente com os produtores".

7 Tradução: "Agricultura Comunitária Sustentada (ASC) é uma associação direta, baseada na relação humana, entre consumidores e um ou mais produtores, na qual os riscos, responsabilidades e benefícios gerados pela atividade agrícola são compartilhados através de um acordo de compromisso a longo prazo".
} 
Association CSA Support Project" traz a definição de CSA : "Community Supported Agriculture means any food, fuel or fiber producing initiative where the community shares the risks and rewards of production, whether through ownership, investment, sharing the costs of production, or provision of labor" (VIRTUAL MAGAZINE SOIL ASSOCIATION, 2011, p. 7).

Para tal estudo, o artigo está organizado em introdução e quatro itens: em "Apontamentos metodológicos e discussões" são apresentadas as metodologias que direcionaram a pesquisa; o item "Economia solidária" aborda as especialidades dessa organização; o trecho "CSAs" reza suas inerentes características e princípios; e o tópico "Das pesquisas de campo" aborda a análise e o tratamento dos dados coletados. Por fim, conclui-se a pesquisa em "Considerações finais", seguidas das "Referências bibliográficas".

\section{APONTAMENTOS METODOLÓGICOS E DISCUSSÕES}

Foram trabalhadas pesquisas qualitativa e quantitativa para descrever o período e a região estudados, as ações dos gestores e a aferição das similaridades e das diferenças numéricas das CSAs. Como lócus principal das pesquisas foram selecionadas as CSAs do Estado de São Paulo: Iperó, no município de Iperó; São José dos Campos, no município de São José dos Campos; Demétria, no município de Botucatu; e Bauru, no município de Bauru.

Os agricultores familiares responsáveis pelas CSAs participaram das pesquisas por meio de questionários abertos contendo questões sobre constituição, produção, registros e contabilidade desses organismos agrícolas. Visitas às CSAs complementaram a coleta de dados por meio da observação e do registro em cadernos de campo.

Vale observar que, ainda, não há parâmetros, métodos ou indicadores referentes às CSAs, por se tratarem de um movimento recente. Desenvolveu-se, todavia, uma ferramenta baseada nos objetivos deste estudo composta por critérios de análise referentes às categorias previamente estabelecidas para elaboração dos questionários, cuja estrutura está visualizada no Quadro 1.

Quadro 1 - Categorias e Critérios de Análises das CSAs estudadas

\begin{tabular}{|c|l|}
\hline \multicolumn{2}{|c|}{ Critérios de Análises } \\
\hline Categorias & \multicolumn{1}{c|}{ Questões para orientar- } \\
\hline $\begin{array}{c}\text { Estrutura de } \\
\text { trabalho }\end{array}$ & $\begin{array}{l}\text { Qual é a natureza jurídica? Há quanto tempo a CSA está em atividade? Qual é a } \\
\text { área da propriedade rural? Qual é a quantidade de produtores na CSA? Qual é } \\
\text { quantidade de coprodutores, cotistas? }\end{array}$ \\
\hline $\begin{array}{c}\text { Capacidade de } \\
\text { cultivo }\end{array}$ & $\begin{array}{l}\text { Quais são os departamentos existentes no organismo agrícola? Qual é o destino } \\
\text { da produção dos produtos cultivados? Qual é a periocidade da entrega das cestas? } \\
\text { Quais são as espécies de vegetais cultivados? }\end{array}$ \\
\hline $\begin{array}{c}\text { Garantia de } \\
\text { orgânicos }\end{array}$ & $\begin{array}{l}\text { Há certificação? Há selo de conformidade orgânica? Quais são as formas de controle } \\
\text { de pragas e doenças? }\end{array}$ \\
\hline Receitas e lucros & Qual é o valor das cestas básicas? Qual é a forma de partilha das receitas na CSA? \\
\hline
\end{tabular}

Fonte: Elaborado pelos autores (2018).

\footnotetext{
${ }^{8}$ Tradução: "Agricultura apoiada pela comunidade significa qualquer iniciativa de produção de alimentos, combustíveis ou fibras em que a comunidade compartilhe os riscos e as recompensas da produção, seja por meio de posse, investimento, compartilhamento dos custos de produção ou fornecimento de mão-de-obra".
} 
No critério "Estrutura de Trabalho" foram elaboradas questões a fim de aferir a fundação, a constituição e os recursos materiais e humanos das CSAs. Em "Capacidade de cultivo", as questões referem-ser à departamentalização, à capacidade do cultivo e à respectiva distribuição, enquanto em "Garantia de Orgânicos" visam a constatar o real cultivo orgânico sem agrotóxicos. Por fim, o parâmetro "Receitas e lucros" fecha a parte contábil, a fim de verificar se alguma categoria de associados ou de gestores é remunerada.

\section{Economia Solidária}

Para as discussões analíticas é essencial que alguns conceitos sobre o tema pesquisado sejam descritos, entre eles o de desenvolvimento solidário, o qual pode ser definido como:

Um processo de fomento de novas forças produtivas e de instauração de novas relações de produção, de modo a promover um processo sustentável de crescimento econômico, que preserve a natureza e redistribua os frutos do crescimento a favor dos que se encontram marginalizados da produção social e da fruição dos resultados da mesma (SINGER, 2004).

Nesse sentido, as forças produtivas são as protagonistas do processo sustentável. Dessa forma, apesar de existirem as revoluções tecnológicas que estimulam a competição nas organizações que visam lucro, os empreendimentos sem fins lucrativos podem quebrar essa corrente de competição capitalista, desde que sejam hegemônicos e autogestionários, como afirma Paul Singer (2004, p. 7).

O desenvolvimento solidário executa os valores da igualdade e da autorrealização com tecnologias agrícolas sob a égide do respeito à natureza, bem como dos valores ambientais, da inclusão social e da autogestão, posto que sua origem vem de pequenas comunidades ou empresas associadas, de cooperativas guiadas pela cooperação e da ajuda mútua entre pessoas e empresas.

Em sentido contrário, advém o desenvolvimento capitalista moldado em grande capital, livre-comércio, competição, propriedade social e política de intervenção mínima do Estado. Consequentemente, o desenvolvimento capitalista exclui o trabalhador assalariado, pois se alicerça sobre o capital e, ainda, cria somente duas classes sociais: empresários e empregados.

No meio desse campo, o desenvolvimento semicapitalista e semissolidário prospera atendendo à flexibilidade, à pequena empresa ou familiar e compartilhando com os empregados os segredos dos negócios, desde o custo do preço. Dessa forma, o conhecimento, nessa parceria, é valorizado com prêmios de produção e de qualidade (SINGER, 2004).

Observa-se que houve um significativo redesenho no papel das cooperativas ao longo dos anos no Brasil, reflexo das alterações das atividades do Estado ante as políticas públicas sociais universais, nos anos da década de 80 do século 20 , reduzindo o montante de investimentos nessa área.

Dessa forma, sob o escudo da livre-concorrência para abertura do mercado ao capital estrangeiro e da não intervenção do Estado no mercado, acelerou-se as privatizações e a redução do Estado nas áreas sociais, obrigando o setor privado a atuar nas políticas sociais locais em que o Estado ficou ausente (MEDEIROS; CUNHA, 2012).

Como modelo de economias solidárias surgem os distritos industriais oriundos da Itália e difundidos na Espanha, em que cada empresa, pequena ou média, integra a mesma linha pro- 
dutiva, num contexto de cooperação e de divisão de trabalhos na rede de empresas do distrito, cujo produto final é executado por uma empresa parceira selecionada. Nesse sentido, vem se promovendo o desenvolvimento de pequenas cidades-comunidades, tais como as províncias de Toscana e Veneto que, em conjunto com outras da região, são denominadas Terceira Itália (SINGER, 2004).

Enfim, nas constituições dos distritos é essencial a cooperação entre as empresas autônomas, dos patrões e empregados, da existência de autonomia das empresas e da aliança envolvendo governo, associações de empregadores e partidos políticos.

Ainda na categoria de organizações solidárias, aparecem os Clubes de troca, que constituem inovação. Originados no Canadá e na Argentina na década de 80 do século 20, nascem de uma situação de recessão, sendo definidos como:

Reunião de pessoas desocupadas que têm possibilidades de oferecer bens ou serviços à venda e precisam comprar outros bens e serviços, mas não podem fazê-lo porque para poder comprar têm antes de vender e no seu meio não há quem tenha dinheiro para poder comprar sem ter vendido antes (SINGER, 2002).

Dessa forma, a ausência de dinheiro consolida essa organização comum em que há muito desemprego. Assim, cada clube cria sua própria moeda, as moedas sociais, sem taxa de juros, por exemplo, o green dólar, o real solidário, a hora de trabalho, entre outros. Consequentemente, "[...] a moeda, como instituição social, recupera a função de laço social e liberta, até certo ponto, os membros dos clubes de troca da dependência da política monetária - frequentemente restritiva - dos guardiões da moeda oficial" (SINGER, 2007).

Por conseguinte, esses carentes satisfazem suas necessidades, adquirem uma nova cultura mercantilista e geram novas amizades e afetividade, abrindo caminhos ao ingresso de outros empreendimentos solidários, tais como cooperativas de compra e venda, de crédito e de produção. Como exemplo, até mesmo serviços de cuidador de criança e idoso são negociados.

As cooperativas surgiram num contexto envolvendo a busca de melhores condições de vida e de trabalho, instrumentalizadas por meio de ações coletivas dos excluídos e marginalizados pelo capitalismo ao longo da história, cuja classe social é determinada em razão da profissão que ocupa (HOCAYEN-DA-SILVA; SILVA, 2021).

Há, finalmente, as cooperativas, que chegaram ao Brasil no século 20 por meio dos imigrantes europeus, inicialmente como cooperativas de consumo e agrícolas. As redes de hipermercados, no entanto, na sua expansão, provocaram falência de grande quantidade de cooperativas de consumo.

Paralelamente, as cooperativas agrícolas cresceram e tornaram-se empreendimentos agroindustriais e empresariais. Singer (2002, p. 122), entretanto, afirma que essas organizações não são típicas economias solidárias autogestionárias, por assalariarem seus diretores e operadores. Vale ressaltar, todavia, que os empreendimentos solidários crescem, durante as crises econômicas, sob uma nova roupagem de cooperativa ou associação produtiva, mas continuam autogestionários.

Esse crescimento que, em parte, foi fomentado pela Conferência Nacional dos Bispos do Brasil (CNBB), acabou por financiar pequenos Projetos Alternativos Comunitários (PAC), dos quais muitos se transformaram em organizações definitivas. Os sindicatos também tiveram pa- 
pel importante nesse crescimento. Além disso, há as cooperativas formadas por trabalhadores que nasceram da falência da empresa em que trabalhavam. Assim, preservam o emprego e se transformam em patrões.

As Universidades também tiveram papel importante na formação de cooperativas, denominadas Incubadoras Tecnológicas de Cooperativas Populares (ITCP), interdisciplinares, compostas por professores, alunos graduados e pós-graduados e empregados. Assim, formou-se uma rede de mais de 80 universidades encabeçadas pela Unitrabalho, em estudos e pesquisas sobre economia solidária.

Diversos fatores, entretanto, devem ser considerados para que haja um ambiente propício ao funcionamento de uma verdadeira economia solidária. Nesse sentido, Singer (2002) contextualiza que:

A economia solidária só teria perspectivas de desenvolvimento se a economia capitalista mergulhasse numa depressão longa e profunda (como a da década de 1930, por exemplo) ou se a hegemonia da burguesia rentista mantivesse a economia da maioria dos países crescendo sempre menos que a elevação da produtividade do trabalho (p. 114).

Logo, nesse contexto, os empreendimentos solidários, no Brasil, não correspondem, tipicamente, a essa modalidade de organização, uma vez que, nas diversas modalidades já elencadas, esse movimento das cooperativas promoveu o assalariamento e a profissionalização de suas gerências. Acerca desse aspecto, o autor ressalta que são solidários por instituírem, na autogestão, os princípios e os valores da solidariedade, da democracia, da igualdade dos empreendimentos, mas não o do assalariamento de seus administradores (SINGER, 2002).

Nesse segmento, em 1995 foi fundada a Agência de Desenvolvimento Social (ADS), associação civil sem fins lucrativos, pela Central Única dos Trabalhadores (CUT); nos anos posteriores, a Fundação Interuniversitária de Estudos e Pesquisas sobre o Trabalho (Unitrabalho), a Federação de Órgãos para Assistência Social e Educacional (Fase) e o Departamento Intersindical de Estatística e Estudos Socioeconômicos (DIEESE), com a finalidade de construir novos espaços e referências de geração de trabalho, renda e inclusão social.

Já em 2003, o governo entrou com sua participação por meio das políticas públicas, criando a Secretaria Nacional de Economia Solidária (Senaes), vinculada ao Ministério do Trabalho, atual da Economia. Faz-se necessário ressaltar, entretanto, que na economia convencional as funções do dono e do empregado são totalmente distintas, enquanto na economia solidária o empregado também participa das decisões, compartilhando-as tais como em cooperativas de agricultura familiar, clubes de troca, entre outros.

Dessa forma, a Economia Solidária está diretamente ligada à proteção do meio ambiente e ao desenvolvimento, tanto que a Secretaria Nacional de Economia Solidária (Senaes) executa, diretamente, o Programa de Desenvolvimento Regional, Territorial Sustentável e Economia Solidária, bem como a solidariedade está entre seus objetivos e diretrizes por meio da manutenção do meio ambiente ecologicamente equilibrado.

\section{Princípios e Políticas Públicas de Economia Solidária}

$\mathrm{Na}$ área do saber, os princípios são tão importantes quanto as leis, devendo ser executados na mesma intensidade. Para tanto, é importante frisar a diferença entre leis ou normas le- 
gais e princípios. Conforme o doutrinador J. J. Gomes Canotilho (2003), regras "[...] são normas que, verificados determinados pressupostos, exigem, proíbem ou permitem algo em termos definitivos, sem qualquer exceção", e continua sua tese:

[...] princípios são normas que exigem a realização de algo, da melhor forma possível, de acordo com as possibilidades fácticas e jurídicas. Os princípios não proíbem, permitem ou exigem algo em termos de tudo ou nada; impõem a optimização de um direito ou de um bem jurídico, tendo em conta a reserva do possível, fáctica ou jurídica (CANOTILHO, 2003, p. 1.255).

Dessa forma, observa-se que os princípios indicam o caminho pelo qual devem seguir as leis. Os princípios são ligados à ética e à moral, sendo imutáveis, enquanto a lei seca e positivada está sujeita às mudanças dos interesses políticos e econômicos.

Os princípios são os ideais estruturantes para que uma organização atinja suas metas e seus objetivos institucionais. Nesse sentido, a organização só se configura como Economia Solidária quando se aplicam os seguintes fundamentos:

- Cooperação: estabelece-se no sentido de compartilhamento dos serviços e, também, das deliberações, sendo mais amigos, como numa propriedade de cultivo e de colheitas coletivas.

- Autogestão: é a capacidade de promover as deliberações de forma coletiva, e não concentrada em uma única pessoa, em que todos têm direito à voz e ao voto nas reuniões.

- Ação Econômica: são as práticas dos atos comerciais, tais como cultivar, produzir, vender, comprar, trocar, transportar, consumir, entre outros, em integração com os demais princípios inerentes à economia solidária.

- Solidariedade: a meta de promover o bem-estar das pessoas está presente em todas as etapas desse processo comercial. Percebe-se a distribuição justa do produto do trabalho na relação solidária com a comunidade e na manutenção do meio ambiente ecologicamente equilibrado.

Nesse contexto, usa-se o Plano Nacional de Economia Solidária, vigente no período de 2015-2019, como ferramenta para a efetividade das políticas públicas com gestão democrática, havendo sido o primeiro a ser construído por meio da $3^{\text {a }}$ Conferência Nacional de Economia Solidária, realizada em Brasília /DF, no período de 26 a 29 de novembro de 2014. Já no ano de 2019, o Conselho Nacional de Economia Solidária (CNES) não convocou nem realizou a $4^{\text {a }}$ Conferência Nacional de Economia Solidária.

As organizações solidárias são constituídas para terem acesso aos produtos e aos serviços ofertados pelo governo em sua política de apoio, tais como: programas públicos de financiamento, compras governamentais, comercialização de produtos e de serviços, assessorias, entre outros; no entanto, estas devem se inscrever, previamente, no Cadastro Nacional de Empreendimentos Econômicos Solidários (Cadsol).

Finalizando os procedimentos de cadastramento, a Declaração de Empreendimento Econômico Solidário (DCSOL) é emitida via internet. Para efetivar o cadastramento, no entanto, a organização solidária deverá preencher os requisitos previstos na Portaria do Ministério do Trabalho e do Emprego n. 1.780/2014: 
- Ser uma organização coletiva, formada por pessoas físicas ou formada por outros empreendimentos, cujos participantes são trabalhadores do meio urbano ou rural;

- Exercer atividades de natureza econômica permanentes, ou ter esse objetivo, no caso de empreendimentos em formação;

- Ser uma organização autogestionária, onde os membros participam da gestão das atividades econômicas e da decisão sobre a partilha dos seus resultados, de forma democrática;

- Ser suprafamiliar, ou seja, ter entre os sócios mais de um núcleo familiar;

- Realizar reuniões ou assembleias periódicas para deliberação de questões relativas à organização das atividades realizadas pelo empreendimento.

Numa próxima etapa, portanto, as organizações solidárias devem elaborar projetos de apoio e de fomento a empreendimentos solidários e submetê-los à aprovação. Obtendo êxito na aprovação do projeto, a Senaes promove a transferência de recursos para os projetos, Estados, municípios e universidades.

\section{CSAS: Princípios, Valores e Características}

Os princípios direcionam o caminho para que as organizações atinjam suas metas e seus objetivos. Também estão presentes entre as CSAs que alicerçam sua estrutura institucional sobre os princípios inerentes, dos quais elencam-se os principais:

- Diversificação das culturas e consumo local: a policultura é diversificada com frutas, legumes e verduras, da própria época, respeitando o calendário agrícola. Por exemplo, na CSA de Wishing Stone Farm, em Rhode Island, nos EUA, são cultivadas 40 espécies distintas de vegetais (HENDERSON; VAN EN, 2007, p. 245).

- Aceitação de alimentos da época: a colheita é feita na época ou na própria estação do ano, mantendo a qualidade do sabor e da nutrição.

- Organização e gestão compartilhada: desde a fundação, agricultores e coprodutores decidem o que contratam, compram e vendem na gestão da CSA, incluindo a administrativa e a financeira, com reuniões periódicas.

- Concessão mútua na decisão dos preços justos: agricultores e coagricultores analisam as planilhas de custos e determinam o preço da cota mensal, incluindo eventuais perdas da safra por estiagem, granizo, enchentes e outras causas.

- Relações de amizade: a amizade e a confiança são características essenciais nas CSAs, por isso troca-se o preço pelo apreço, saindo das relações de venda e consumo, patrão e empregado, vendedor e consumidor, entre outros.

- Distribuição independente: após montar a cesta com os alimentos, o agricultor a distribui, sem custo de transportadora, por meio de um dos seguintes processos: os coagricultores buscam na CSA; o agricultor transporta a um ponto de distribuição na cidade, comercial ou residencial, para o recebimento dos coagricultores; ou o agricultor leva, diretamente, até a casa do coagricultor.

- Aprendizagem e ajuda mútua: o coagricultor interage, ativamente, desde o plantio até a colheita com o agricultor, assim melhora a relação entre homem do campo-cidade, ajudando a resolver os problemas da CSA, e, ainda, participa de palestras de temas afins e de visitas à propriedade rural e às colheitas. 
- Estabilidade e apreço: os trabalhos são desenvolvidos de forma estável, exigindo paciência e cooperação. Antes, o agricultor gastava tempo e recursos materiais com as vendas, por exemplo, em feiras; agora, deixando de ser feirante, possui a tranquilidade de que o pagamento das cestas mensais está garantido durante todo mês, mesmo em épocas de chuvas intensas, quando pouco se colhe. Dessa forma, a cultura do preço é substituída pela do apreço.

Enfim, o exercício desses princípios e valores favorece os laços de confiança, afetividade e solidariedade, criando uma comunidade sólida e fraterna.

\section{Princípios das CSAs Comuns aos da Economia Solidária}

As CSAs e as organizações de Economia Solidária têm em comum os núcleos familiares que aplicam os princípios essenciais ao funcionamento dessas organizações, conforme apresentado no Quadro 2 e detalhado para cada um deles a seguir.

Quadro 2 - Princípios e valores comuns das CSAs e das Economias Solidárias

\begin{tabular}{|c|c|c|c|}
\hline Princípios e valores & CSAs & $\begin{array}{l}\text { Economias } \\
\text { Solidárias }\end{array}$ & Em comum \\
\hline Cooperação & Sim & Sim & Cooperação \\
\hline Autogestão & Sim & Sim & Autogestão \\
\hline Ação econômica & Sim & Sim & Ação econômica \\
\hline Solidariedade & Sim & Sim & Solidariedade \\
\hline Diversificação de culturas e consumo local & Sim & Não & Não \\
\hline Aceitação de alimentos da época & Sim & Não & Não \\
\hline Relações de amizade & Sim & Sim & Relações de amizade \\
\hline Distribuição independente & Sim & Não & Não \\
\hline Organização e gestão compartilhada & Sim & Sim & $\begin{array}{l}\text { Organização e gestão } \\
\text { compartilhada }\end{array}$ \\
\hline $\begin{array}{l}\text { Concessão mútua na decisão dos preços } \\
\text { justos }\end{array}$ & Sim & Não & Não \\
\hline Aprendizagem e ajuda mútua & Sim & Sim & $\begin{array}{c}\text { Aprendizagem e ajuda } \\
\text { mútua }\end{array}$ \\
\hline Estabilidade e apreço & Sim & Sim & Estabilidade e apreço \\
\hline
\end{tabular}

Fonte: Elaborado pelos autores (2018).

- Princípio da Cooperação, em que se compartilham os serviços e as deliberações, está presente, também, nas CSAs por meio dos Princípios da Organização e Gestão Compartilhada. Assim como no Princípio de Concessão Mútua na Decisão dos Preços Justos, o produtor e o consumidor pactuam sobre os preços das cotas mensais.

- Princípio de Autogestão, em que as deliberações são colegiadas, e não individuais, também é vivenciado pelas CSAs por intermédio do Princípio da Gestão CompartiIhada (Quadro 2), em que agricultores e coagricultores fazem reuniões ordinárias e assembleias gerais para deliberações. 
- Princípio da Ação Econômica, em que se praticam os atos comerciais de compra, venda, produção, troca, consumo, entre outros, é aplicado nas CSAs. Por meio do Princípio de Concessão Mútua na decisão dos preços justos, os coagricultores autorizam os agricultores familiares a comprarem máquinas e instrumentos de trabalho.

- Princípio da Solidariedade, que valoriza o bem-estar em todas as etapas do processo produtivo, com a distribuição justa do produto do trabalho, respeitando o meio ambiente e a sustentabilidade. É aplicado nas CSAs mediante os Princípios da Relação de Amizades entre coagricultores, numa relação de confiança entre as partes.

Pode-se verificar que os princípios e os valores essenciais das Economias Solidárias são, integralmente, vivenciados pelas CSAs, o que as aproxima de uma organização típica de Economia Solidária.

\section{DAS PESQUISAS DE CAMPO E DOS RESULTADOS}

Superando a fase de conceitos, definições e princípios, os trabalhos avançaram para as coletas de dados diretamente nas CSAs localizadas no interior do Estado de São Paulo, especificamente no recorte territorial: Iperó, no município de Iperó; São José dos Campos, no município de São José dos Campos; Demétria, no município de Botucatu; e Bauru, no município de Bauru, enquanto o temporal foi no período de 10 a 14 de outubro de 2018.

As entregas das cestas aos coagricultores da CSA Demétria ocorrem, semanalmente, às sextas-feiras (Figura 1). Parte dos alimentos é entregue no próprio organismo agrícola, enquanto as demais são encaminhadas aos pontos de entrega. Nos dias de entrega estão sempre à disposição, para escolha do coagricultor, a cesta 1, composta por brócolis, alho poró, alface crespa, couve-flor, repolho, batata $(500 \mathrm{~g})$ e cenoura $(500 \mathrm{~g})$, e a cesta 2 , contendo rúcula, alface mimosa, escarola, acelga, espinafre, beterraba e cebola (500g).

A CSA Demétria tem como especialidade o Banco de Sementes com mais de 1.000 espécies e possui parceria, inclusive, com a Empresa Brasileira de Pesquisa Agropecuária (Embrapa), segundo o agricultor responsável. Há sementes crioulas, geneticamente melhoradas naturalmente, e espigas de milho em diversas cores (Figura 2).

Figuras 1 e 2 - CSA Demétria

\begin{tabular}{|c|c|}
\hline Figura 1 - Entrega de cestas & Figura 2 - Sementes crioulas e milhos \\
\hline & \\
&
\end{tabular}


As pesquisas de campo junto as CSAs selecionadas para este estudo apuraram, na categoria 1 (Constituição), que todas as comunidades optaram por instituir a formalidade jurídica à organização (Quadro 3, grupo 1, alínea "a") por meio da inscrição no Cadastro Nacional de Pessoa Jurídica (CNPJ), o que confere obrigações tributárias e trabalhistas, mas as beneficia com direitos sociais.

Quadro 3 - Comparativo do resultado das pesquisas de campo junto as CSAs

\begin{tabular}{|c|c|c|c|c|}
\hline \multirow{2}{*}{ Grupo de questões } & \multicolumn{4}{|c|}{ Comunidades que Sustentam a Agricultura - CSAs } \\
\hline & Iperó & S.J. Campos & Demétria & Bauru \\
\hline \multicolumn{5}{|l|}{ 1- Constituição } \\
\hline a) Natureza jurídica & CNPJ & CNPJ & CNPJ & Associação \\
\hline b) Período de funcionamento, em anos & 5 & 6 & 9 & 8 \\
\hline c) Área organismo agrícola, por hectares (ha) & 23,1 & 4,5 & 10 & 12 \\
\hline d) Agricultores & 3 & 3 & 14 & 20 \\
\hline e) Coagricultores & 52 & 35 & 185 & 125 \\
\hline \multicolumn{5}{|l|}{ 2-Produção } \\
\hline a) Departamentos dos organismos agrícola & 5 & 2 & 4 & 9 \\
\hline b) Destino alimentos cultivados para CSA & $40 \%$ & $100 \%$ & $50 \%$ & $50 \%$ \\
\hline c) Periodicidade da entrega das cestas & Semanal & Semanal & Semanal & Semanal \\
\hline d) Espécies de vegetais cultivados & 70 a 80 & 35 & 62 & 70 \\
\hline \multicolumn{5}{|l|}{ 3-Registros } \\
\hline a) Certificações & SPG & SPG & SPG & SPG \\
\hline b) Selo de conformidade & Org. br & Não tem & Não tem & IBD \\
\hline c) Controle pragas e doenças & $\begin{array}{c}\text { Caldas em } \\
\text { geral }\end{array}$ & $\begin{array}{c}\text { Sem } \\
\text { agrotóxicos }\end{array}$ & Caldas & $\begin{array}{c}\text { Sem } \\
\text { agrotóxicos }\end{array}$ \\
\hline
\end{tabular}

Fonte: Elaborado pelos autores (2018).

Os levantamentos também constataram que essas organizações estão em atividade entre cinco e nove anos (Quadro 3, grupo 1, alínea "b") e, por serem ainda novas no mercado, permite-se reafirmar que esse modelo agrícola tem ingressado, no Brasil, há pouco mais de uma década.

Em relação à área territorial, verifica-se que contemplam entre 4,5 e 23,1 ha (Quadro 3, grupo 1, alínea " $c$ "), sendo, portanto, considerados empreendimentos de extensão pequena, quando comparados às grandes fazendas da agricultura convencional. Isso ocorre, no entanto, por serem administradas por agricultores familiares, os quais, para se integrarem aos programas das políticas públicas, devem ter até quatro módulos fiscais (artigo 3º, item I da Lei 11.326/2006 que trata da Política Nacional da Agricultura Familiar e Empreendimentos Familiares Rurais).

O número de agricultores varia de três a 20 (Quadro 3, grupo 1, alínea "d") para cada CSA, refletindo, proporcionalmente, o tamanho da propriedade e a capacidade produtiva de cada organismo agrícola. Essa mesma linha de justificativa explica o número de coagricultores variando de 35 a 185 (Quadro 3, grupo 1, alínea "e"). 
Em relação à categoria "Produção", na alínea "a", a departamentalização atinge entre dois e nove por CSA, reflexo da estrutura administrativa de cada organismo agrícola, que pode exercer os seguintes setores de atividades: horta, floresta, compostagem, minhocultura, criação de animais soltos, floricultura, apicultura, piscicultura, pomar, entre outros.

No destino da produção agrícola somente a CSA de São José dos Campos encaminha $100 \%$ aos coagricultores (Quadro 3, grupo 2, alínea " $b$ "). Observa-se que os agricultores familiares também eram feirantes, e a migração para esse modelo agrícola foi ocorrendo por etapas, conforme foi ganhando confiança e estabilidade econômica.

A entrega semanal das cestas contendo legumes, verduras e frutas consagrou-se por unanimidade (Quadro 3, grupo 2, alínea "c"). Dentre as CSAs pesquisadas, a de São José dos Campos iniciou suas atividades com o fornecimento das cestas quinzenais, mas, com o avanço da demanda, passou a ser semanal. Essa logística advém tanto dos agricultores, que têm o costume de fazer feiras semanais, quanto do consumidor, que compra dessa forma, observando serem alimentos perecíveis.

A variedade de vegetais cultivados é grande - de 35 a 80 (Quadro 3, grupo 2, alínea "d") -, configurando a policultura, modelo contrário à monocultura, predominante na agricultura convencional. Ressalta-se que o consumidor deseja alimentos nutritivos e saudáveis, que são encontrados mais facilmente na maior variedade de vegetais.

A categoria "3 - Registro" - engloba o formalismo da documentação, envolvendo as certificações e os selos (Quadro 3, grupo 3, alínea "a" e "b"), que comprovam serem produtos orgânicos, observando a preferência dos agricultores pesquisados pelo Sistema Participativo de Garantia da Qualidade Orgânica (SPG). Essa opção deve-se ao fato de que, com a SPG, o custo é menor, o processo é menos burocrático e a produção não necessita de selo orgânico quando a venda é feita diretamente ao consumidor.

Em contrapartida, a outra opção seria as certificadoras por auditoria. O seu custo, entretanto, é alto, por acumularem mais procedimentos e onerações nos seus credenciamentos, os quais envolvem até os requisitos de orgânicos internacionais (Decreto n. 6.323/2007, que regulamenta a Lei n. 10.831/2003 dispondo sobre a agricultura orgânica).

Para o controle de pragas e de doenças os resultados mostraram que os agricultores empregam calda bordalesa e meios naturais (Quadro 3, grupo 3, alínea " $\mathrm{C}$ "), acompanhando as diretrizes da agricultura orgânica, que impede o uso de agrotóxicos.

As CSAs pesquisadas apresentaram dados semelhantes, mas com algumas especialidades, o que reflete o fato de haver pouco tempo de fundação, por adotarem os mesmos valores e princípios e pertencerem, culturalmente, ao mesmo Estado.

Enfim, os agricultores são remunerados em todas as CSAs pesquisas por meio do pagamento das cotas mensais, das quais são extraídas as despesas, e o valor remanescente, consistente num certo porcentual, configura o lucro da atividade desenvolvida. Dessa forma, as CSAs não são típicas Economias Solidárias, segundo o estudos da tese de Paul Singer.

\section{CONSIDERAÇÕES FINAIS}

As CSAs estudadas representam o modelo alternativo de agricultura sustentável, promovendo o desenvolvimento regional num contexto que resgata a identidade do agricultor e beneficia o consumidor com alimentos saborosos, nutritivos e orgânicos. 
O desenvolvimento regional opera por meio do associativismo entre os agricultores e consumidores, gerando, assim, empregos, alimentos e rendas aos trabalhadores rurais e suas famílias, consequentemente aumentando o consumo e a circulação de produtos e serviços na comunidade rural.

Constatou-se, também, que as parcerias entre os agricultores e os coagricultores formalizam-se por meio de associações ou cooperativas, numa relação direta de cooperação e de confiança por meio de contrato de adesão à CSA.

Esses organismos agrícolas, realmente, configuram-se como organização promotora do desenvolvimento sustentável: praticam os pilares ou as dimensões da sustentabilidade, de forma socialmente justa, ambientalmente equilibrada e economicamente viável, por meio, respectivamente, da prática do preço justo, do cultivo por Sistema Agroflorestal e do valor rentável das cotas.

Assim, os dados apontam para organizações que vivenciam os princípios da cooperação, da autogestão e da solidariedade mediante o exercício da organização e da gestão compartilhadas, a concessão mútua na decisão de preços justos e a relação de amizades respectivamente.

A autogestão presente na Economia Solidária e nas CSAs consiste na capacidade de seus parceiros, conselheiros e trabalhadores envolvidos promoverem as suas decisões administrativas, financeiras e produtivas.

Os estudos verificaram que as CSAs não são típicas economias solidárias, isso por destinarem um valor ao agricultor como margem de lucro. Segundo Singer (2002), toda cooperativa que assalaria seus gestores descaracteriza-se como organização de economia solidária.

Verifica-se, no atual governo federal, que o Programa Nacional de Economia Solidária, como política pública, não realizou a 4 $4^{a}$ Conferência Nacional de Economia Solidária em 2019. Dessa forma, não há Plano Nacional de Economia Solidária 2020-2024, o que pode interromper a continuidade desses serviços públicos essenciais à população.

Assim, a divulgação, por meio da mídia, do funcionamento desses organismos agrícolas e dos resultados positivos alcançados, poderia contribuir para o avanço desse modelo agrícola alternativo em outras regiões, municípios e Estados.

Além disso, as CSAs podem otimizar recursos e aumentar a produtividade, tornando-se mais atrativas aos consumidores conscientes por meio de parcerias, inclusive com outras CSAs, e de um bom plano de mídia sobre as vantagens para a saúde alimentar e nutricional.

Logo, o presente artigo, na área das economias solidárias e da agricultura orgânica, representada pelas CSAs, avançou nessa literatura escassa no Brasil, na conceituação e na apuração dos resultados das pesquisas de campo.

Assim, constitui-se uma estrutura agrícola capaz de promover o desenvolvimento regional por meio da geração de empregos e rendas, inclusive valorizando o agricultor satisfeito em produzir, ao seu semelhante, alimentos sem agrotóxicos, numa disposição que promove a sustentabilidade sob as dimensões ecológica, econômica e social.

\section{AGRADECIMENTOS}

Agradecemos ao Núcleo de Pesquisa e Documentação Rural (Nupedor) e ao Programa de Pós-Graduação em Desenvolvimento Regional e Meio Ambiente da Universidade de Araraquara (Uniara) pelas orientações técnicas ao presente trabalho. 


\section{REFERÊNCIAS}

BRASIL. Supremo Tribunal Federal. Uso social da propriedade. ADI 2.213-MC, rel. min. Celso de Mello, julgamento em 4-4-2002, Plenário, DJ de 23-4-2004. Disponível em: https://stf.jusbrasil.com.br/jurisprudencia/774884/medida-cautelar-na-acao-direta-de-inconstitucionalidade-adi-mc-2213-df. Acesso em: 10 mar. 2020.

CANOTILHO, José Joaquim Gomes. Direito constitucional e teoria da constituição. 7. ed. Coimbra: Almedina, 2003.

HENDERSON, Elizabeth; VAN EN, Robyn. Sharing the harvest: a citizen's guide to Community Supported Agriculture. Printed in the United States of America. Revised Edition, nov. 2007.

HOCAYEN-DA-SILVA, A. J.; SILVA, A. H. da. Protagonismo das cooperativas na promoção dos objetivos de desenvolvimento sustentável: reflexões teóricas e agenda de pesquisa. In: Desenvolvimento em Questão, v. 19, n. 54, p. 83-103, 2021. DOI: 10.21527/2237-6453.2021.54.83-103. Disponível em: https://www. revistas.unijui.edu.br/index.php/desenvolvimentoemquestao/article/view/10336. Acesso em: 13 jun. 2021.

IPEA. Instituto de Pesquisa Econômica Aplicada. RC-IPEA - Repositório do Conhecimento do IPEA. In: SILVA, S. P. Artigo: Crise de Paradigma? A Política Nacional de Economia Solidária no PPA 2016-2019. Revista Economia Solidária e Políticas Públicas. Mercado de Trabalho, v. 64, ed. abr. 2018. Disponível em: http:// repositorio.ipea.gov.br/handle/11058/8393. Acesso em: 25 fev. 2020.

MEDEIROS, A. C.; CUNHA, E. V. da. Economia solidária e desenvolvimento local: a prática dos empreendimentos econômicos solidários na região do Cariri cearense. In: Desenvolvimento em Questão, v. 10, n. 21, p. 61-87, 2012. DOI: 10.21527/2237-6453.2012.21.61-87. Disponível em: https://revistas.unijui.edu.br/ index.php/desenvolvimentoemquestao/article/view/353. Acesso em: 13 jun. 2021.

MINISTÉRIO DA ECONOMIA. Secretaria do Trabalho. Economia solidária. Disponível em: http://trabalho. gov.br/trabalhador-economia-solidaria/quem-sao-os-participantes. Acesso em: 10 mar. 2020.

MINISTÉRIO DA ECONOMIA. Secretaria do Trabalho. Plano Nacional de Economia Solidária. Disponível em: http://trabalho.gov.br/trabalhador-economia-solidaria/plano-nacional-de-economia-solidaria. Acesso em: 10 mar. 2020.

TEM. Ministério do Trabalho e Emprego. Portaria n. 1.780 de 19/11/2014 - Institui o Cadastro de Empreendimentos Econômicos Solidários - CADSOL. Disponível em: https://www.legisweb.com.br/legislacao/?id=277278. Acesso: 8 abr 2018.

ONU. Organização das Nações Unidas. Conferências das Nações Unidas. Meio ambiente e desenvolvimento sustentável. Disponível em: https://nacoesunidas.org/conferencias-de-meio-ambiente-e-desenvolvimento-sustentavel-miniguia-da-onu/. Acesso em: 31 jan 2020.

ONU. Organização das Nações Unidas. Declaração da Conferência das Nações Unidas sobre o Meio Ambiente Humano - 1972. Disponível em: https://apambiente.pt/_zdata/Politicas/DesenvolvimentoSustentavel/1972_Declaracao_Estocolmo.pdf. Acesso em: 10 mar 2020.

ONU. Organização das Nações Unidas. Declaração do Rio Sobre Ambiente e Desenvolvimento. A Conferência das Nações Unidas sobre Ambiente e Desenvolvimento no Rio de Janeiro de 3 a 14 de junho de 1992. Disponível em: https://apambiente.pt/_zdata/Politicas/DesenvolvimentoSustentavel/1992_Declaracao_Rio.pdf. Acesso em: 10 mar. 2020.

ONU. Organização das Nações Unidas. Organização Mundial de Saúde. OMS. Disponível em: https://www. paho.org/bra/index.php?option=com_content\&view=article\&id=5263:opas-oms-apoia-governos-no-objetivo-de-fortalecer-e-promover-a-saude-mental-da-populacao\&Itemid=839\#: :text=A\%20constitui\%C3\%A7\%C3\%A30\%20da\%200rganiza\%C3\%A7\%C3\%A30\%20Mundial,de\%20transtornos\%20mentais\%20 ou\%20defici\%C3\%AAncias. Acesso em: 10 mar 2020.

PLANALTO. Legislação. Política Nacional da Agricultura Familiar e Empreendimentos Familiares Rurais. Lei n. 11.326, de 24 de julho de 2006. Disponível em: http://www.planalto.gov.br/ccivil_03/_Ato20042006/2006/Lei/L11326.htm. Acesso em: 10 mar. 2020.

PLANALTO. Legislação. Política Nacional do Meio Ambiente. Lei n. 6.938, de 31 de agosto se 1981. Disponível em: https://www.planalto.gov.br/ccivil_03/Leis/L6938.htm. Acesso: 31 jan. 2020.

SINGER, Paul. Introdução à economia solidária. 1. ed., $6^{\text {a }}$ reimpressão. São Paulo: Editora Fundação Perseu Abramo, 2002. Disponível em: https://bibliotecadigital.fpabramo.org.br/xmlui/bitstream/handle/123456789/22/Introducao-economia-solidaria-WEB-1.pdf?sequence=1. Acesso em: 16 mar. 2020. 
SINGER, Paul. Desenvolvimento capitalista e desenvolvimento solidário. Revista de Estudos Avançados, Universidade de São Paulo, v. 18, n. 51, p. 22, 2004. Disponível em: http://www.revistas.usp.br/eav/article/view/9997/11569. Acesso em: 24 fev. 2020.

SINGER, Paul; ORTEGA, A. C.; FILHO, N. A. (org.). Desenvolvimento territorial, segurança alimentar e economia solidária. Campinas, SP: Editora Alínea, 2007. (Capítulo X. Economia Solidária e Socialismo, Paul Singer, p. 255-260).

SORDI, V. F.; VAZ, S. C. M. Os principais desafios para a popularização de práticas inovadoras de agricultura inteligente. In: Desenvolvimento em Questão, v. 19, n. 54, p. 204-217, 2021. DOI: 10.21527/22376453.2021.54.204-217. Disponível em: https://www.revistas.unijui.edu.br/index.php/desenvolvimentoemquestao/article/view/10891. Acesso em: 13 jun. 2021.

VIRTUAL MAGAZINE SOIL ASSOCIATION. The impact of community supported agriculture. Published November, 2011. Disponível em: https://communitysupportedagriculture.org.uk/wp-content/uploads/2015/03/The-impact-of-community-supported-agriculture.pdf. Acesso em: 10 mar. 2020. 